\title{
O REVERSO DA MOEDA: PRÁTICASTEORIAS NAS REDES EDUCATIVAS POUCO DEMOCRÁTICAS EM TEMPOS DE PANDEMIA
}

\author{
Marcelo Machado ${ }^{\mathrm{i}}$ \\ Maria Morais ${ }^{\text {ii }}$ \\ Noale Toja ${ }^{\text {iii }}$
}

\begin{abstract}
Resumo: Em tempos de pandemia, quase todas as estruturas consolidadas do planeta foram modificadas, como a restrição da circulação de pessoas. Na educação, uma nova forma foi apresentada para dar continuidade ao ano letivo nas escolas, chamado de estudo remoto. Os usos dos artefatos tecnológicos, muitas vezes proibidos nos espaçostempos escolares, tornaram-se uma possibilidade de continuarmos tecendo conhecimentossignificações. Pretendemos escrever sobre as implicações desenvolvidas nesses novos cotidianos. Como se estabeleceram esse 'outro lado da moeda' quando dependemos da tecnologia, das apropriações e os desafios encontrados para as partes envolvidas, além de compreender quais foram as práticasteorias aplicadas em um momento em que a democratização do ensino se viu profundamente afetada.
\end{abstract}

Palavras-chave: Coronavírus; Artefatos tecnológicos; Cotidianos; Democratização do ensino.

\section{LA INVERSIÓN DE LA MONEDA: PRÁCTICAS TEÓRICAS EN LAS PEQUEÑAS REDES EDUCATIVAS DEMOCRÁTICAS EN TIEMPOS DE PANDEMIA}

Resumen: En tiempos de pandemia, se modificaron casi todas las estructuras consolidadas del planeta, como la restricción de la circulación de personas. En educación, se presentó una nueva forma de continuar el año escolar en las escuelas, llamada estudio remoto. Los usos de los artefactos tecnológicos, que a menudo están prohibidos en los espacios escolares, se han convertido en una posibilidad para que podamos seguir tejiendo conocimientos y significados. Tenemos la intención de escribir sobre las implicaciones desarrolladas en estas nuevas vidas cotidianas. ¿Cómo se estableció esta 'otra cara de la moneda' cuando dependemos de la tecnología, las apropiaciones y los desafíos que enfrentan las partes involucradas, además de comprender qué teorías se aplicaron en un momento en que la democratización de la educación se vio profundamente afectada?

Palabras clave: Coronavirus; Artefactos tecnológicos; Diário; Democratización de la educación.

\section{Introdução}

Em questões de semanas, suspender, em todo o mundo e ao mesmo tempo, um sistema econômico que até agora nos diziam ser impossível desacelerar ou redirecionar. A todos os argumentos apresentados pelos ecologistas sobre a necessidade de alterarmos nosso modo de vida, sempre se opunha o argumento da força irreversível da "locomotiva do progresso", que era capaz de tirar dos trilhos, "em virtude", dizia-se , "da globalização". Ora, é 
justamente seu caráter globalizado que torna tão frágil o famoso desenvolvimento, o qual, bem ao contrário, pode sim ser desacelerado e finalmente parado (LATOUR, 2020, p.3).

Para Latour (2020), a atual crise socioeconômica e política provocada pela pandemia do coronavírus, conhecida cientificamente como COVID-19, tem provocado mudanças estruturais e sociais que pareciam solidificadas há décadas. Grande parte do planeta está sob direta influência do vírus que se alastrou rapidamente, deixando a população do planeta sob o jugo da contaminação, nos fazendo perceber o quanto estamos conectados por meio de um vírus e que somos, todos, agentes e agenciadores de doenças. Estas conexões também nos tornam responsáveis por romper sua rede de transmissão. Passamos a ser responsáveis uns pelos outros.

Esta situação colocou a nós humanos, enquanto espécies, em total estado de vulnerabilidade e de responsabilidade. Percebemos que somos ínfimos diante de um microorganismo que ironicamente controlou o mundo e suas grandes potências, como diria Raul Seixas e Paulo Coelho em sua melodia poética "o dia em que a Terra parou". Este mesmo vírus, por sua vez, nos permitiu enxergar além das necessidades individuais e perceber que somente a organização coletiva e a criação de medidas preventivas e assistidas, serão capazes de bloquear a continuidade da propagação do vírus de modo acelerado e em larga escala, como temos visto acontecer em outras partes do planeta.

$\mathrm{O}$ isolamento social, atual situação em que vivemos, foi a principal medida regulamentada para evitar a propagação do vírus. Essa busca pela desaceleração tornou-se essencial, dentre as possibilidades principais e palpáveis, pelo menos a uma parte da população - para evitar a propagação do vírus e o contágio de mais pessoas. Vivemos um presente em que os modos de ser, estar e compreender o mundo estão se modificando. Estamos num presente. Vivendo um novo presente a cada dia. As incertezas nos levaram a esquecer o passado e evitar a projeção do futuro. Um vírus nos isolou, como se congelasse o nosso presente. Isso nos coloca diante da vida de uma maneira em que somos obrigados a nos ver a cada instante, no agora, nas ações de cada acontecimento, percebendo o sentido de cada uma delas, porque só temos a certeza do agora e do momentâneo. Com isso, nossa responsabilidade se tornou maior com o desdobramento da vida que está aí a ser criada.

Ainda que o isolamento social seja uma orientação e não se constitua, como uma determinação legal, somos afetados por múltiplos sentimentos que nos perpassam e alteram nossos modos e nossa psiquê. Muitos não estão indo ao trabalho, à empresa, à academia, à feira, ao cinema, ao teatro, ao museu, às escolas/universidades, às casas de parentes ou 
amigos. Às vezes, temos a sensação que vivemos em um ano que não 'existe', uma vida em suspensão ou uma vida se recriando para um algo outro, totalmente novo e desconhecido.

Entretanto, em meio a todo esse caos e desnormalização, as demandas da vida funcional têm colocado desafios para professores e estudantes das diversas redes educativas brasileiras que, por orientação dos respectivos órgãos reguladores precisam dar continuidade ao ano letivo vigente - um modus operandi ensinado e aprendido no movimento do trem -, são desafiados a reinventar suas práticas educativas com o auxílio vital de artefatos como os das tecnologias digitais e mídias sociais. Que pasmem: foram tão demonizados em seus cotidianos escolares!

Estamos na iminência de viver a educação que só pode acontecer na troca e no aprenderensinar $^{i v}$ entre sujeitos que estão enredados via conectividade virtual. A ambiência virtual (SANTOS, 2019) e a era pós-mídia (GUATTARI, 1997) se tornam um possível espaçotempo, um lócus capaz de promover o encontro entre os diferentes praticantespensantes - educadorese estudantes, entrelaçados em virtualização e atualização (ALLIENZ, 1996) de realidades, criando outras ambiências como sala de aula. Uma ambiência criada por outras interferências, revelando intimidades para além da sala de aula. Preocupados e afinados em fazer entre o possível e o melhor, tentam se apropriar de novos processos criativos e da potência formativa que os ciberespaços têm, em tempos complexos. Então nos perguntamos como esses processos se dão? E são democráticos em atender aos "brasis" tão plurais?

Instigados a compor essa edição, sob o mote "Educação e Democracia em tempos de pandemia", nos propusemos a pensar sobre as questões acima. Ademais, buscamos relatar sobre esse outro lado da moeda: quando os usos (CERTEAU, 2012) dos artefatos tecnológicos se tornam imprescindíveis para a formação de conhecimentossignificações, na medida que, sempre foram negligenciados, na maioria das vezes, proibidos nas escolas. E para nos apoiar acerca desses espraiamentos, traremos as nossas vivências, através dos nossos relatos enquanto professores, mediadores e pais de estudantes, de como tem sido fazer educação em tempos de pandemia.

\section{As redes educativas em tempos de pandemia}

Concordamos com Nilda Alves (2016), que nos traz a importância de reconhecermos as conexões que fazemos nas inúmeras redes educativas, as quais formamos e que nos formam como praticantespensantes, seja como educadores, seja como estudantes. Com a Revista Interinstitucional Artes de Educar. Rio de Janeiro, V. 6 - N. Especial II - p. 140-165 (jun - out 2020): "Educação e Democracia em Tempos de Pandemia”. DOI: 10.12957/riae.2020.51880 
autora, pensamos que estas redes "sãoformadas pelos seres humanos em suas múltiplas e complexas relações e nas quais eles se formam com os outros" (ALVES, 2016, p.235). Essa forma de fazerpensarsentir as pesquisas em educação, como ela propõe com as pesquisas nosdoscom os cotidianos e nos explica através da atualização desses movimentos dos cotidianos, junto com Andrade e Caldas (2019):

\begin{abstract}
Nas pesquisas com os cotidianos partimos da ideia de que pensar as práticas cotidianas de viver dentro e para além das macro-negociações políticas e econômicas permite nos aproximar da complexidade da vida sem abrir mão de todas as redes que formamos e nas quais nos formamos. Neste sentido, nunca buscamos estudar sobre os cotidianos mas, estudar nos/dos/com os cotidianos, assumindo a nossa total implicação neste processo, entendendonos, sempre, como neles mergulhadas. Estudar e pesquisar com os cotidianos de pessoas comuns, com as histórias comuns que nos são contadas - porque nessas pesquisas as narrativas (todos os sons) e imagens contam encontrando nestas, sentimentos e 'conhecimentossignificações' que seus 'praticantespensantes' (OLIVEIRA, 2012)criam, exigiu admitir a riqueza e complexidade desses 'espaçostempos'. (ANDRADE, ALVES, CALDAS, 2019, p.1)
\end{abstract}

Acreditamos que em todas essas redes são formados "mundos culturaisdiversos" (ALVES, 2016, p.236). E neste pensamento ela identifica e nomeia sete dessas redes, que são as seguintes: a das práticasteorias da formação acadêmica; a das práticasteorias pedagógicas cotidianas; a das práticasteorias das políticas de governo; a das práticasteorias coletivas dos movimentos sociais; a das práticasteorias das pesquisas em educação; a das práticasteorias de produção e 'usos' de mídias; a das práticasteorias de vivências nas cidades (no campo ou à beira das estradas) (ALVES, 2016). Neste escrito vamos enfatizar três: as práticasteorias pedagógicas cotidianas - buscando entender como essa rede agiu diante da pandemia - as de produção e 'usos' de mídias e tecnologias digitais - para entender os mecanismos usados por estudantes e professores - e as práticasteorias das políticas de governo - que vão guiar nossos passos neste período com tantas adversidades.

Entendemos as redes como espaçostempos de criação e circulação de conhecimentos e fazeressaberes. Neste momento de pandemia da COVID-19, entendemos que existem muitos desafios para estarmos reunidos, no entanto, com uso de artefatos tecnológicos podemos, de alguma forma, continuarmos nossos processos formativos e de atuação política. Para Certeau (2012), os 'usos' que fazemos de artefatos tecnológicos ou culturais são mais importantes que os artefatos em si. A maneira com a qual lidamos e o modo como operamos se tornam mais relevantes, ou seja, como nos apropriamos em conversas com o outro, dos artefatos digitais, como celulares, computadores, aplicativos, câmera, microfone, headphone, redes de internet - 
wi-fi, banda larga, dados, enfim tecnologias, mídias, redes sociais virtuais, que estão impregnadas nos nossos fazeressaberes, mas até então negligenciados nos processos educativos dentro da escola ou em sala de aula.

Acreditamos que seja importante destacar pelas nossas vivências, que já usamos tudo isto em processos educativos, porém, na maioria das vezes fora da sala de aula. Diante dessa impressão, queremos nesse artigo narrar nossas experiência nos diferentes cotidianos, e ao mesmo tempo buscar compreender como são feitos os usos desses artefatos tecnológicos, e como estes usos são capazes de nos auxiliar nesses espaçostempos remotos.

Concordamos com Alves (2019) e partimos do pressuposto de que as redes educativas são também tecidas com as práticasteorias de produção e usos das mídias. Para a autora, "os professores, hoje em exercício se formaram com o uso cotidiano da televisão e das chamadas redes sociais" (ALVES, 2019, p. 131). Atualmente, os usos das redes sociais da internet, como alguns aplicativos e programas, permitem os encontros online entre os grupos de pesquisa, professores com seus estudantes, reuniões pedagógicas e diretivas e até com pais dos estudantes. Nesta plataforma, tem sido possível trocarmos vivências, relatos, transpor conteúdos disciplinares, provocar questionamentos, estranhamentos e problematizações de temas cotidianos vividosaprendidos nesse tempo de tantas provocações, que nos faz sair de uma suposta normalidade, de uma zona de conforto/confronto, para brincar com as palavras. A ambiência virtual tem sido o lugar mais recorrido nestes tempos para criação de fazeresaberes e conhecimentossignificações.

É possível observar que os artefatos tecnológicos, por muitos ignorados durante anos, são objetos de desafeto de alguns professores. Martin Barbero (2000) entende que crianças e jovens possuem "facilidade de entrar e manipular a complexidade das redes informáticas" (BARBERO, 2000, p.86). Por sua vez, os adultos, sobretudo alguns educadores, têm a ilusão de uma ameaça de seu poder pelos fazeressaberes de seus estudantes, que têm um domínio acerca dos usos das tecnologias digitais. Para o autor, os adultos muitas vezes "desvalorizam e tornam obsoletos muitos de seus saberes e habilidades" (BARBERO, 2000, p.86). Porém as crianças e jovens dessas últimas duas décadas já nasceram e cresceram num mundo digital e virtual, e a internet fabrica um ambiente, como diz Maturana (2002), de linguajeio, que seria a linguagem criada neste ambiente, que seriam, por exemplo, as abreviações e apropriações de palavras, criação e uso de memes, entre outros.

Em tempos de pandemia, o processo de ensinoaprendizagem ocorre especialmente no ciberespaço. Para entendermos como este processo de ensinoaprendizagem continua vivo, camaleonicamente se adaptando a todas essas transformações, precisamos estar atentos para 
essas novas relações que se tecem em redes, especialmente nas virtuais. Estamos dentro deste processo, afetados por ele, e afetando aos Outros (MATURANA, 2002) diante de tantas mudanças radicais. Os Outros, no entendimento do autor, seriam outras pessoas, objetos, situações, tudo aquilo que está em relação aos afetos. E no meio desse emaranhado de sentimentos, emoções e crenças, tecemos outras maneiras de criação de conhecimentossignificações.

\section{Os artefatos tecnológicos - o outro lado da moeda}

Bugou... Algo entrou no sistema e corrompeu os dados, como disse Pitty: "Pane no sistema, alguém me desconfigurou!" (na música Admirável chip novo). Um vírus se reproduz em códigos programados para infectar um sistema. Ele se aloja a partir de uma transmissão de dados, seja uma imagem, som, texto; e quando o hardware for desenvolver uma determinada tarefa, acionar tal dispositivo, onde o vírus se alojou, boom!!! Já era, o sistema foi corrompido, os dados foram roubados. Isto se faz como obra das tecnologias que nós mesmos criamos. Somos criadores de tudo, dos artefatos mais rudimentares aos mais sofisticados, todos muito bem elaborados. E nos colocamos reféns de nossas criações ou as subestimamos e demonizamos, dependendo do nosso interesse e intenção.

Esta relação também se dá acerca das maneiras que fazemos usos das imagens e sons, dos quais somos bombardeados a todo momento. Seja nas ruas, televisões ou redes sociais da internet. Com estas imagens e sons pensamos, criamos e chegamos a muitas possibilidades. A imagem que trouxemos abaixo é um meme, que tem um incrível poder de circulação nas redes e muitas apropriações sociopolíticas.Em geral, o meme pode ser "definido como uma imagem/texto com intencionalidade de transmitir uma ideia" (ALMEIDA et al, 2019, p. 60). A Universidade Federal Fluminense (UFF) iniciou um museu ${ }^{\mathrm{v}}$ online com a história desses memes, que é definido na página como: "um fenômeno típico da internet, e pode se apresentar como uma imagem ou analogia, uma frase de efeito, um comportamento difundido, um desafio. Memes são geralmente efêmeros.

Figura 1 - Meme sobre a educação em tempos de pandemia 

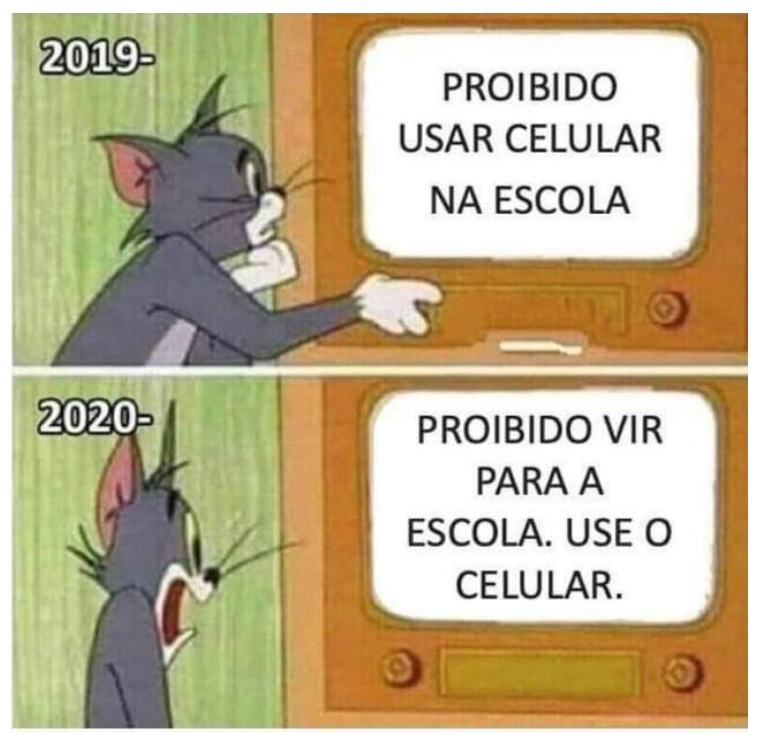

Fonte: Imagem capturada nas redes sociais da internet (whatsApp).

Com essa imagem pensamos em muitas possibilidades acerca da temática proposta como o uso da tecnologia digital e a relação com os cotidianos escolares. Trabalhamos com a ideia de 'personagens conceituais' a partir dos usos feitos por Alves (2012), que se apropria da ideia de Deleuze e Guattari (1992), que trata os personagens conceituais não como um conceito em si, mas o que se cria em conversas com o outro, pois somente com elas somos capazes de formar teorias, criar 'conhecimentossignificações'. Este outro, são inúmeros outros, pessoas, filmes, música, imagens, sons, cheiros, artefatos, tecnologias.

Alves (2012) nos inspira com seus modos de usar a ideia de "personagens conceituais" em suas pesquisas. Ela enfatiza as narrativas produzidas nas "conversas" como "personagens conceituais", assim como as imagens e os sons:

os personagens conceituais são, assim, aquelas figuras, argumentos ou artefatos que entram como o outro - aquele com que se 'conversa' e que permanece presente muito tempo para que possamos acumular as ideias necessárias ao desenvolvimento de conhecimentos e a compreensão de significações nas pesquisas que desenvolvemos. Esses personagens conceituais aí têm que estar, para que o pensamento se desenvolva, para que novos conhecimentos apareçam, para que lógicas se estabeleçam. É nessa mesma direção que afirmamos que para as pesquisas nos/dos/com os cotidianos, as narrativas (e sons de diversos tipos) e as imagens dos praticantes docentes e de outros praticantes dos 'espaçostempos' cotidianos não podem ser entendidas, exclusivamente, como 'fontes' ou como 'recursos metodológicos'. Elas ganham o estatuto, e nisso está sua força, de personagens conceituais. Sem narrativas (sons de todo o tipo) e imagens não existe a possibilidade dessas pesquisas. Assim, ao contrário de vê-las como um resto rejeitável, dispensável do que buscamos, algo sempre igual e repetitivo, é preciso tê-las, respeitosamente, como necessárias aos processos que realizamos (2012, p. 12-13). 
Diante disto, nos apresentamos como forma de pensarmos e dialogarmos sistematicamente com o (ex)posto e com outras pessoas. Os autores que inspiram Alves, vão nos dizer sobre isso que:

o personagem conceitual aparece por si mesmo muito raramente, ou por alusão. Todavia, ele está lá; e, mesmo não nomeado, subterrâneo, deve sempre ser reconstituído pelo leitor. Por vezes, quando aparece tem um nome próprio: Sócrates é o principal personagem conceitual do platonismo. Muitos filósofos escreveram diálogos, mas há perigo de confundir os personagens de diálogo e os personagens conceituais: eles só coincidem nominalmente e não tem o mesmo papel. O personagem de diálogo expõe conceitos: no caso mais simples, um entre eles, simpático, é o representante do autor, enquanto que outros, mais ou menos antipáticos, remetem a outras filosofias, das quais expõem os conceitos, de maneira a prepará-los para as críticas ou modificações que o autor lhes vai impor. $O$ personagem conceitual, em contrapartida, opera os movimentos que descrevem o plano de imanência do autor, e intervém na própria criação de seus conceitos. Assim, mesmo quando são "antipáticos", pertencem plenamente ao plano que o filósofo considerado traça e aos conceitos que cria: eles marcam então os perigos próprios a este plano, as más percepções, os maus sentimentos ou mesmo os movimentos negativos que dele derivam, e vão, eles mesmo, inspirar conceitos originais cujo caráter repulsivo permanece uma propriedade constituinte desta filosofia" (DELEUZE; GUATTARI, 1992, p. 85-86).

Assim, pensamos acerca de como as tecnologias são tratadas na ambiência escolar. Desde de 2002, foi criada a primeira lei, em Minas Gerais, que proibia o uso de aparelhos eletrônicos em sala de aula (Rodrigues et al, 2018). Depois disso, diversas outras leis foram criadas em âmbitos municipais, estaduais e federal, todas proibitivas do uso de aparelhos celulares ou outros aparelhos eletrônicos nas salas de aula. O que justificaria tal lei? Quais os perigos que os avanços tecnológicos, como celular e outros artefatos eletrônicos podem comprometer os processos educativos? Com isso percebemos uma negação aos avanços técnicos e tecnológicos que se produziam. Existia uma tentativa de limitar os currículos escolares, não dialogando com os progressos sociais presentes.

Se por um lado a sociedade caminha na busca pela construção de relações cada vez mais dinâmicas e flexíveis, através de práticas inovadoras; por outro lado, a escola fica aprisionada por uma legislação proibitiva, que colabora ainda mais para tornar o espaço escolar obsoleto em suas práticas educativas (RODRIGUES ET AL, 2018, p. 111).

"Ensinar não é transferir conhecimento, mas criar as possibilidades para sua própria produção ou a sua construção" (FREIRE, 2003, p. 47). Pensamos que a respeito dessas 
normas proibitivas, despontencializa-se tecnologias contemporâneas que fazem parte dos nossos cotidianos, inclusive para estudar. Ao contrário disso, devemos investigar como os usos de celulares, por exemplo, que é o que temos de mais disseminado, como um artefato tecnológico e linguagem multimodal, atribui valores formativos e criativos nos processos de aprendizagem. O uso consciente das tecnologias precisa ser discutido nos espaçostempos escolares, e a sua relação no dentrofora das escolas públicas e privadas no país. Os estudantes e os professores se relacionam durante todo o tempo, havendo muitos encontros físicos e outros virtuais.

É inegável que a inserção das tecnologias no contexto educacional necessita ser reconhecida, e pensada, de modo a estabelecer momentos de comunicação inteligente, através de projetos que flexibilizem as diversas vias de interação entre educandos e educadores, oportunizando a vivência de um processo comunicacional entre seus pares, bem como possam tornar favorável o uso potencial dos diversos recursos e funções dos aparelhos celulares, como, por exemplo, atividade de captura e edição de imagem e vídeo, organização de listas musicais, agenda virtual, recursos da tv, e/ou aplicativos com diversos serviços disponíveis e gratuitos (RODRIGUES ET AL, 2018, p. 117).

Os praticantespensantes que estão no chão da escola, vivenciando os cotidianos escolares, com todas as suas camadas de poder e vigilância entendem a grande dificuldade dos usos de tecnologias em suas aulas. Acreditamos que isso se dá, porque não se explora a fundo a potência das tecnologias. A exemplo disso, na década de 1990 com a criação da TV Escola, foram distribuídos aparelhos de TV, antenas parabólicas, vídeo cassete e receptores de canais de TVs educativas. Esses equipamentos ficavam engradados, aprisionados, sem uso, ou com usos restritos apenas para cumprir um manual curricular. Ainda assim, se criava uma crença limitante na operacionalidade de tais equipamentos, que por sinal, estes estavam nas casas da maioria dos brasileiros.

Atualmente, com o advento dos celulares multimodais, banda larga, serviço de dados e outras táticas de acesso dos praticantespensantes, percebemos que não há mais controle acerca desses usos. E é isso que amedronta. Aos professores? Aos gestores? Talvez não, mas a um sistema educacional ainda arcaico, dominador que acredita que pode controlar o pensamento e a criação proibindo usos de tecnologias nas escolas e esvaziando a potencialidade das escolas ou dos processos educativos quando não disponibiliza os acessos livres aos professores e estudantes. Inútil.

Porém, este mesmo sistema posa de pós-moderno e de uma educação na era pós-mídia criando canais educativos, plataformas nas secretarias de educação de municípios, estados e 
federação. Ainda faz usos limitados e ditatoriais com as redes de wi-fi e banda larga, ainda restritos aos grandes centros, enquanto que a própria tecnologia dos celulares disponibiliza um exercício a autonomia, por criar sistemas intuitivos e de fácil operacionalidade. Um exemplo de governo facilitador desse acesso seria o nosso vizinho Uruguai, onde as redes de wi-fi são gratuitas e acessadas em vias públicas.

Esses sistema disciplinador estruturante, delega a responsabilidade de controle às direções e chefias diretas, que proíbem os usos, fiscalizam as salas, andam como se fossem patrulhas e a tecnologia é vista como um inimigo a ser perseguido. Entendemos, que cada praticantepensante precisa ter autonomia para decidir quais são os melhores usos das novas tecnologias, mas o que estamos relatando são o quanto as políticas de currículos negligenciaram estes artefatos.

Os currículos 'oficiais' e mínimos - prática comum em muitas redes de ensino - não dialogam com esses, nem tão novos, artefatos tecnológicos. Fazemos usos em alguns momentos, cobramos manejo em trabalho de pesquisa, mas de fato, ainda não foi absorvido pela legislação e pelas escolas. É importante ampliar esta conversa nas redes educativas acerca da importância dos usos que podemos fazer socialmente, sejam eles bons ou maus usos, entendendo inclusive as responsabilidades que temos uns com os outros, sobretudo, com o quê publicamos como produção, criação, reprodução e replicação de mensagens, imagens sons, imbuídos de intencionalidades.

É justamente neste cenário, que trazemos o primeiro meme que brinca com o uso das tecnologias no ano de 2019 e 2020. Em tempos de pandemia, de uma hora para outra, temos que fazer usos desses artefatos (cada um em sua casa) para podermos produzir conhecimentossignificações, e assim, salvar um ano letivo tão complexo e perturbado.

Professores que não tinham experiência com o ensinoaprendizagem online, tiveram que aprender a gravar aulas, dar aulas em tempo real aos seus estudantes, usar seus próprios equipamentos tecnológicos, suas próprias bandas largas de internet, sem que houvesse qualquer planejamento e aprendizados prévios da missão a ser desempenhada. É claro que nesse momento, muitos professores acessaram suas redes de conhecimento e assim foram aprendendoensinando no afã de salvar o ano letivo. Mas com que qualidade? E a que preço? Emocionalmente e financeiramente estavam amparados?

Sendo o Brasil um país de dimensões continentais e extrema desigualdade social, como ficam os professores, que em geral são mal remunerados, que não tem artefatos tecnológicos, que não dão conta de atender essa demanda de governo? E ainda nas escolas particulares, onde os professores tiveram exigências ainda maiores para justificar as 149 Revista Interinstitucional Artes de Educar. Rio de Janeiro, V. 6 - N. Especial II - p. 140-165 (jun - out 2020): "Educação e Democracia em Tempos de Pandemia". DOI: 10.12957/riae.2020.51880 
mensalidades pagas pelos pais? E o mesmo fato ocorrendo com os estudantes? Sem acesso a internet de qualidade, sem equipamentos adequados, sem espaço reservado para os estudos em suas moradias.

Figura 2 - Meme sobre a educação em tempos de pandemia

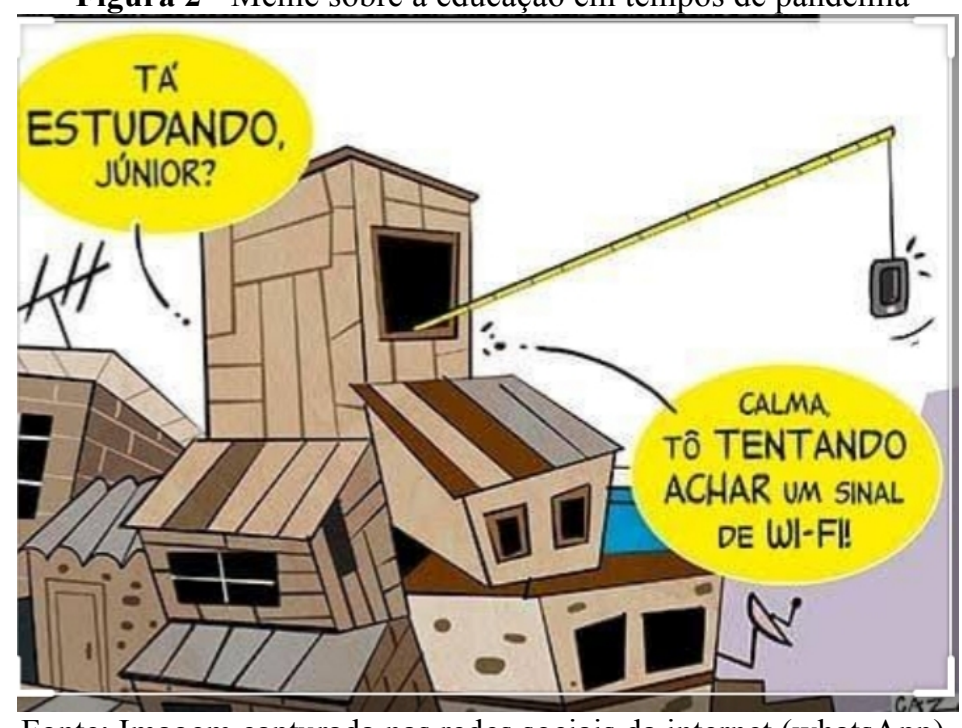

Fonte: Imagem capturada nas redes sociais da internet (whatsApp).

Essa educação online, que do dia para a noite foi estabelecida por profissionais não qualificados para atuarem nessa modalidade de ensino e que não teve seu currículo adaptado para o momento, onde não houve o acompanhamento de quem não se "enquadrou", sem a infraestrutura necessária a todos os envolvidos nesse processo precisa ser repensada.

Figura 3 - Meme sobre a educação em tempos de pandemia

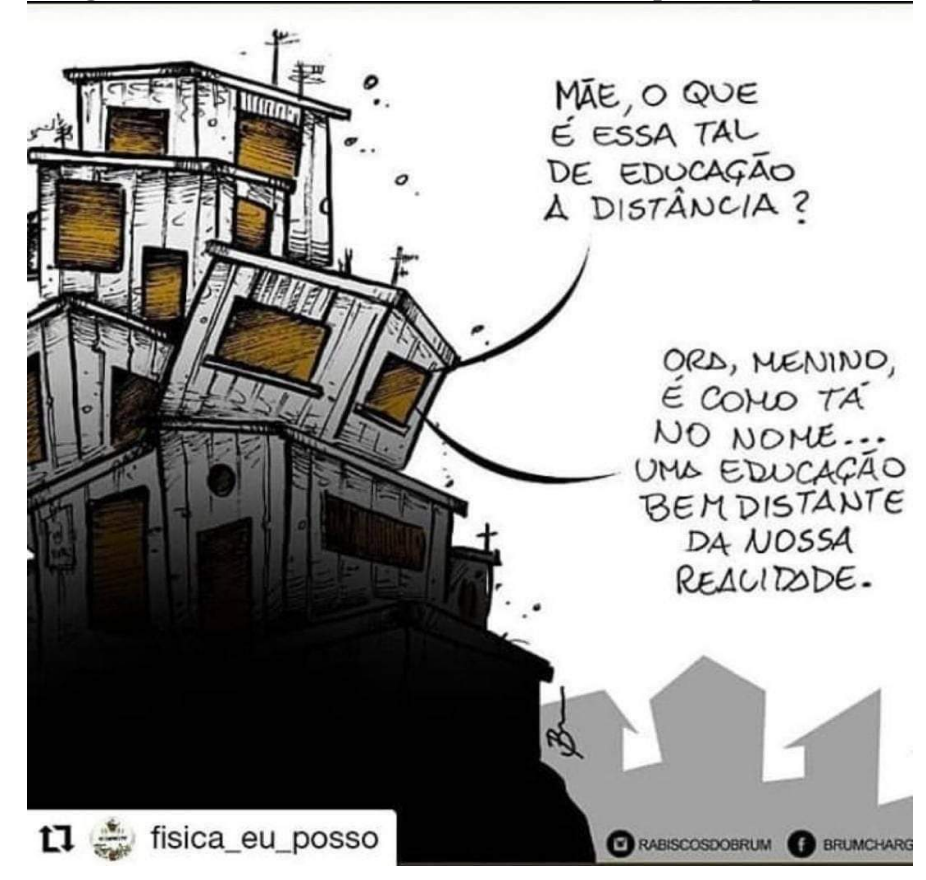

Fonte: Imagem capturada nas redes sociais da internet (whatsApp). 
O relato dos pais foi de desespero porque tiveram que acompanhar seus filhos como verdadeiros mediadores escolares. Ora para decifrar o conteúdo, ora para auxiliá-los com o artefato tecnológico, ora para dar conta de seu próprio trabalho, ora para dar conta das tarefas da casa. Isso no caso de quem tem o artefato tecnológico, pois quem não o tem, vivencia a educação a distância como algo distante da realidade das camadas da população mais carentes.

Estudantes da educação infantil e do ensino fundamental dos anos iniciais e finais, do dia para a noite, se viram realizando tarefas no computador com os conteúdos escolares. Ora, a infância necessita de interação, de atividades colaborativas, da mediação dos professores. E ainda, como manter os estudantes atentos em frente a um computador por horas para cumprir os tempos de aula? Estar juntos é possível por meio de aplicativos como zoom, meet e outros mas exige que todos tenham garantidos esses recursos, o que não é o caso da maioria dos estudantes e professores brasileiros pelo que já foi exposto. E quanto a esse tempo e a dinâmica, ela precisa ser adequada a cada faixa etária, a cada objetivo de aula. E é claro, repensar a forma de avaliação.

Pensamos que o mais adequado para esse momento de pandemia fosse que a escolas, cada uma com suas particularidades, pensassem reunidos virtualmente, de acordo com as possibilidades de cada lugar, quais as melhores soluções para seus estudantes. Pensar juntos que o processo educacional está dentro de um contexto sócio-econômico-cultural que precisa ser respeitado.

Esse é o momento de repensar práticas, adequar currículos, reestruturar as avaliações que na sua maioria são apenas conteudistas. E os espaçostempos? Redefini-los. Enquanto não houver vacinação em massa, o vírus permanece como uma ameaça, portanto, salas de aula lotadas, atividades esportivas de contato, eventos culturais, entre outros, estão longe de serem possíveis nos ambientes educacionais.

Temos neste momento uma grande oportunidade de repensar tudo: a educação, a forma como tratamos o planeta, as relações de trabalho, as relações familiares...

Ouvimos muitos relatos de estudantes, principalmente mulheres, que narram as dificuldades encontradas em seus cotidianos. Elas chamam atenção para a sobrecarga de trabalho e o abalo emocional de todo esse momento. Muitas são professoras e estão vivendo o ser "professora a distância" e o ser "mãe de estudantes online" com todas os desafios expostos neste artigo; além disso, possuem as tarefas da casa, onde ainda predomina a responsabilidade feminina e mais, nesse contexto de pandemia, o abalo emocional da perda de entes queridos. Então, como ter vontade de estudar mediante a um cenário que causa tanto 151 2020): "Educação e Democracia em Tempos de Pandemia”. DOI: 10.12957/riae.2020.51880 
estranhamento, que nos tira de uma zona de conforto, em que temos que nos reinventar. E nós docentes, devemos avaliar os estudantes com normalidade? Este será outro desafio para os próximos capítulos que a saga da COVID-19 nos convida a pensar ainda em 2020.

Porém, como Certeau (2012) nos mostra que diante dos acontecimentos e nas situações mais adversas fazemos usos de táticas e astúcias e criamos linhas de fuga, para driblar as adversidades. Os acontecimentos da pandemia reforçam nosso potencial criativo e a ideia de que aprendemos a partir da nossa necessidade e do nosso interesse em resolver uma questão, um problema, encontrar soluções. A aprendizagem pautada por currículos ou conteúdos distantes da realidade apresenta fragilidades impossibilidades. Mesmo com todos os percalços, percebemos que somos capazes de aprender em meio aos desafios, ou dos problemas como em matemática, física, história, língua portuguesa, geografia, artes e por aí vai...

No início, pode até causar insegurança, aflição, ansiedade e frustração ou não, porque cada pessoa sente diferente, com o passar das experiências com os fazeressaberes tecnológicos, professores, estudantes e familiares, praticantespensantes deste processo, vão se ajudando e compartilhando seus aprendizados, forjando na virtualidade, atualizações na criação de conhecimentossignificações, desmistificando a ideia de falta de preparo, porque o preparo acontece no fazer.

\section{Novas práticasteorias para as novas relações praticantespensantes}

Diante deste cenário, nos indagamos quais são as praticasteorias realizadas nos cotidianos que permitam compreender e abarcar todas essas variáveis colocadas até aqui no texto. Assim, nós autores, iremos desencadear alguns pensamentos acerca das muitas realidades que estamos vivenciando.

Somos todos professores, pesquisadores, mães/pais, responsáveis, estudantes, em um emaranhado de redes que nos entrelaçam e nos atravessam em muitos contextos (co)existentes. No entanto, nossas vivências cotidianas nos permitem ter um lugar de fala e compartilhar um pouco sobre o que vemosouvimossentimospensamos acerca desta educação remota, que nos foi (im)posta em meio ao caos pandêmico.

Falamos, assim, daquilo que estamos participando, atuando, em diversas frentes. Nossas praticasteorias se mostram novas, (ou nem tão novas assim), mas são praticadas em forma de ação pedagógica em um momento em que não estamos vivendo em nossas plenitudes, enquanto humanos, diante do tamanho desafio: permanecer os processos 
formativos educacionais num mundo tão transfigurado e com tantas notícias que nos abalam como o estado necropolítico brasileiro, as perdas de vidas humanas e os impactos socioeconômicos, como as ameaças de cortes salariais e perdas de emprego.

Em suma, nossas práticasteorias, deste momento, estão sendo feitas de modo online com uso de plataformas e mídias sociais da internet. Os encontros passam a ser via tela do computador ou celular e as atividades redigidas dessa forma, a distância. Os usos tão condenados da tecnologia na sala de aula, se mostram necessários em dias atuais.

A seguir traremos três narrativas para esta conversa (dos três autores do texto), uma que é mãe de filhas que estão no $6^{\circ}$ ano do ensino fundamental e $2^{\circ}$ ano do ensino médio, ambas de escola pública; outro professor de geografia, profissional de escola pública e privada; e a última que é professora de ensino a distância (EAD) do curso de licenciatura em Pedagogia.

\section{Práticasteorias sentidasouvidaspensadas pelas mães}

Meu relato surge a partir do que sinto, percebo e penso ao verouvir as conversas nos processos de aprendizagem das minhas filhas com suas professoras e professores, colegas e outros familiares que se juntam nos grupos de WhatsApp. Desta forma, compreendo todos estes personagens conceituais (DELEUZE e GUATTARI, 1992) como praticantespensantes nestas redes educativas. Nunca a aprendizagem esteve tão dentrofora das escolas. Os muros foram rompidos por redes virtuais, códigos, em que nossas vistas não alcançam. Aparentemente não há fronteiras para este processo criativo.

Durante estes acontecimentos, eu aqui em minhas tarefas profissionais e de estudos, me encontro imersa nos afazeres domésticos de maneira mais rotineira e no cumprimento das demandas das filhas, que pela proximidade do dia a dia, as percebemos com mais intensidade. Estou vendo as espinhas em seus rostos e os cabelos sendo pintados. Posso abraçar com mais tempo e ajudar nos trabalhos da escola, ouvindo os professores em tempo quase real, com leve delay, dando suas aulas com seus desafios tecnológicos, mas com uma alegria de superar certos mitos, e melhor, com a colaboração de seus estudantes.

Ouvindo uma dessas palestras de youtube do filósofo Leandro Karnal, no qual gosto muito, embora tenha coisas que não sinto da maneira como ele aborda ou pensa, mas ele disse uma coisa acerca desse processo tecnológico que estamos passando, isto em 2018: a escola ainda está apegada a cópia e a memorização e não a potencialização da inteligência e com o advento e a popularização da internet, com a globalização dos conteúdos, informação e Revista Interinstitucional Artes de Educar. Rio de Janeiro, V. 6 - N. Especial II - p. 140-165 (jun - out 2020): "Educação e Democracia em Tempos de Pandemia”. DOI: 10.12957/riae.2020.51880 
conhecimentos, as pessoas não recorrem mais às bibliotecas e enciclopédias, ou seja, aos livros tais como eles são. As pessoas vão a internet para pesquisar aquilo que for de seus interesses. Ele continua, que até poucas décadas atrás, e brinca, na época da "moral e cívica" e do diploma de datilografia, o que era valoroso era a quantidade de informações que o sujeito retinha, o nome das capitais, de rios, todas as datas etc. Atualmente o que precisamos nos ocupar como formadores, educadores, é como potencializamos a inteligência desenvolvendo a crítica a partir dos conteúdos e do que buscamos nos processos de aprendizagem. E aí as tecnologias digitais e informáticas são responsáveis por esse paradigma. Ao mesmo tempo Karnal pondera, que o excesso de informação não garante formação, por isso o papel do educador, do professor, mediar as relações dos usos das mídias contemporâneas, trazendo para a conversa a expansão da inteligência pela crítica e pela criação de seu próprio aprendizado.

Expandiremos algo se exercitarmos, se nos colocarmos na potência de superar os desafios nos fazeressaberes, desta forma, poderemos encontrar outros modos de existência.

Voltando ao ambiente doméstico, ouvi algumas professoras de uma das minhas filhas investigando com sua turma a maneira de tornar as aulas mais produtivas e democráticas. Em busca de acordos para atender aos estudantes, que estavam fora daquela rede virtual (que necessita de usos de aplicativos com câmeras e som, exigindo conexões mais robustas), houve a diversificação dos meios utilizados para o contato: como o uso whatsapp, aplicativo mais acessível, já que muitas operadoras não cobram pelo uso.

Em coordenações consensuais de ações, criando um ambiente de linguajeio (MATURANA, 2002), o grupo se organiza para estudar com as professoras e os estudantes, e também se ajudarem entre si; da mesma forma, como os estudantes ajudam a professora a se virar com a tecnologia.

Em uma dessas aulas, eu ouvia a professora com uma certa emoção agradecendo aos estudantes pelo aprendizado que ela estava tendo com eles. Ela chegou a dizer que estava aprendendo mais do que ensinando, e agradeceu pela paciência da turma. Eu no meu canto fiquei emocionada e não me contive fui cumprimentar esta professora. Por esse motivo, Nilda Alves sempre nos coloca queaprendemosensinamos em nossa relação com os estudantes, ou seja, o aprender vem primeiro abandonando aquela velha lógica de que o professor ensina e o estudante aprende.

Assim como esta professora, ouvi, percebi, outras professoras expressando sentimentos semelhantes. Da mesma forma que existem professores que ainda encontram dificuldades, talvez ainda por resistência, e quem resiste, creio que sofra mais. Existem Revista Interinstitucional Artes de Educar. Rio de Janeiro, V. 6 - N. Especial II - p. 140-165 (jun - out 2020): "Educação e Democracia em Tempos de Pandemia”. DOI: 10.12957/riae.2020.51880 
também estudantes que para fugir das aulas usam suas astúcias e criam suas narrativas para justificar suas ausências nos encontros. Quero dizer com isso, que nestas redes aparecem todas as singularidades e multiplicidades de desejos, comportamentos, anseios, gestos e fragilidades. Nós, como humanos criadores das tecnologias, ainda temos medo de nossas criaturas.

Outro paralelo, são as aulas da minha filha do sexto ano, na qual recebe todos os dias conteúdo de pelo menos duas matérias pelo grupo do facebook da escola e no grupo de responsáveis no whatsapp, para que possamos acompanhar o processo e também se ajudarem no grupo.

Tenho acompanhado mais de perto as aulas de história, geografia e artes que são aquelas que minha filha solicita mais apoio. E lendo os textos, no que tange seu conteúdo e sua abordagem, eles são mais criativos, produtivos, críticos e atuais do que dos livros didáticos, habitando no linguajeio daquele grupo. Tenho observado que os professores, ou a equipe de orientadores, gestores, que envolve toda a produção desse outro modo de aprenderensinar, estão se desaprisionando de modos convencionais, conservadores e tradicionais nos gestos de criação de conhecimentossignificações de maneira compartilhada, em co-criação revelando processos democráticos nestes fazeressaberes, inspirando movimentos de "conservAmores".

Interessante ressaltar que temos uma geração de estudantes que nasceu na era tecnológica e por esse motivo está acostumada ao ambiente das exposições. Percebemos que estes estudantes se interessam em ser protagonistas no processo de aprenderensinar, na criação de conhecimentossignificações. Para eles é muito interessante produzir um vídeo, tanto quanto assistí-lo.

Democratizar faz parte da criação de políticas e disponibilização de insfraestrutura, mas também pode estar para além disso na ação de criar autonomias responsáveis.

Em um dos trabalhos de arte de uma de minhas filhas, sentamos as três para realizá-lo. Fizemos uma releitura da obra do norueguês Edvard Munch de 1893, o Grito, versando com o momento da pandemia. Ao final do mesmo, onde cada uma de nós elaborou a sua percepção da obra, queríamos que minha filha enviasse todos a professora. 
Figura 4 - Quadro O Grito, inspiração para o trabalho sobre a pandemia

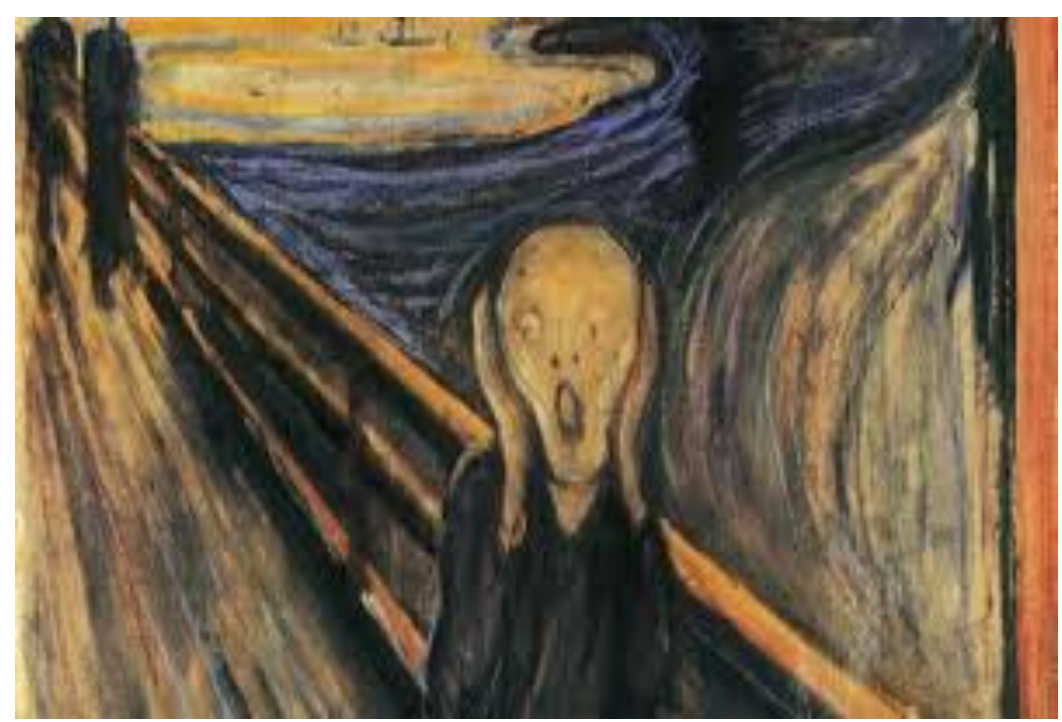

Fonte: wikipidia.com

Figura 5 - Trabalhos elaborados por mim (mãe) e minha filha

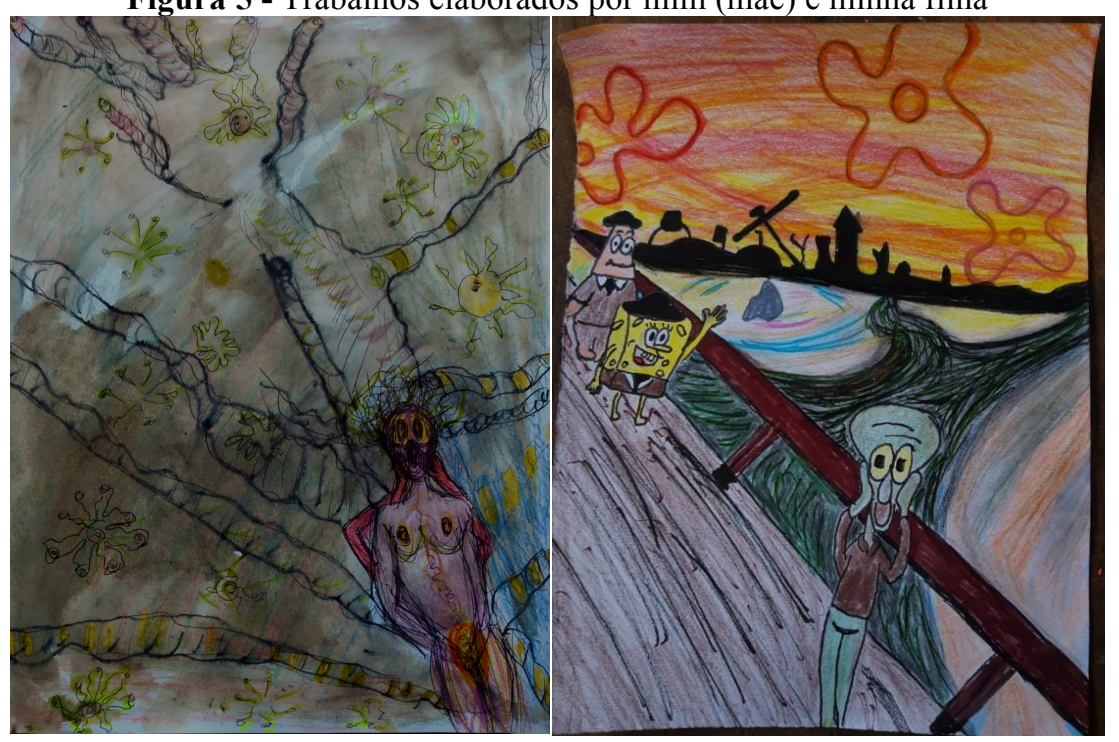

Fonte: arquivo pessoal da autora.

É evidente que estou criando uma narrativa a partir de uma condição favorável, diferente de muitos brasileiros. Parece que estou romantizando uma situação caótica, não quero causar esta impressão. Porém o caos nós já o conhecemos, porque estamos vivendo dentro dele. A dor que estamos passando neste momento singular, mas não diferente de tantos outras que este planeta já atravessou, como guerras, fome em muitos territórios, muitas injustiças sociais e outras. É importante salientar que existe um déficit que envolve a economia e a compaixão, mas que sobretudo continuamos criando.

Quis trazer no meu relato experiências positivas para percebermos dentro da crítica, desta expansão da nossa inteligência, como propõe Karnal, como podemos repensar os 
processos educativos com os currículos conectados aos acontecimentos, com os cotidianos. Evidenciar estas experiências como mãe e educadora é sentir a potência deste currículo atravessado, nos e pelos, espaços físicos, nas salas de aula, nos corredores, nos pátios, com os encontros presenciais, nos abraçando, nos beijando, tocando nas mãos, olhando nos olhos, coisas que também não fazíamos mais, porque temos mais olhos para as telas dos celulares. E junto a isto compreender dentro deste processo, o espaço virtual da internet, quanto o próprio virtual que está em imanência, em constante processo de atualização como nos diz Deleuze (1997), e num remoto controle, como diria Adriana Calcanhotto (1992).

\section{Vivenciando as diferenças entre as escolas públicas e privadas em tempos de pandemia}

O MEC (Ministério da Educação) aprovou em meio à pandemia do coronavírus, uma resolução que valida às horas de aulas dadas pelas plataformas online, que de acordo com o parecer do Conselho Nacional de Educação (CNE), permite a homologação deste tempo para o cumprimento das horas mínimas do ano letivo. Sendo assim, é reconhecida a validade das aulas remotas (ou onlines), tendo ainda alguns pontos sendo discutidos: como a questão dos exames e avaliações.

Para efeitos deste artigo, vou relatar minhas vivências enquanto professor das rede pública estadual e privada do Rio de Janeiro (estado e município). As aulas foram interrompidas em 16/03/2020, com o decreto do Governador do Estado Wilson Witzel, que colocou em estado de recesso coletivo para professores, alunos e funcionários das escolas públicas estaduais. Assim, as aulas retornam em estado remoto a partir de 30/03/2020, utilizando a plataforma Gsuites, da Google, como ferramenta para continuidade do processo formativo.

Enquanto professor da rede, fomos submetidos a essas condições de trabalho de modo muito repentino, como o mundo todo, não houve preparação, curso ou suporte para darmos continuidade a aprendizagemensino de modo online, e como vou tratar neste artigo como uma educação remota. Para Renata Costa (2020) o "ensino remoto praticado atualmente [na pandemia] assemelha-se a EAD apenas no que se refere a uma educação mediada pela tecnologia. Mas os princípios seguem sendo os mesmos da educação presencial"(Revista Desafios da educação, 2020). Com isso, entendemos as diferenças existentes entre essas duas formas de educação - à distância/remota - e as implicações trazidas em nossas vidas cotidianas. 
Sendo as mesmas plataformas digitais usadas nas duas instituições de ensino, não tem como não fazermos comparações existentes entre as duas realizações aplicadas: o acesso aos meios tecnológicos são, sem dúvida, um fortíssimo fator limitante para continuidade dos processos formativos.

Divido meu tempo entre as aulas da instituição pública e privada, ambas funcionam de maneira remota. Meu lugar de fala é enquanto professor do Ensino fundamental dos anos finais ( $6^{\circ}$ ao $9^{\circ}$ ano) e Ensino médio. A primeira, respectivamente, permite flexibilidade do uso de sistema. Professores podem colocar as atividades na plataforma, deixando que os alunos acessem de forma assíncrona. Eles podem ver vídeos, acessam textos, acessam exercícios e respondem as atividades propostas. A segunda permanece como em horário presencial: professores e estudantes se encontram no aplicativo Google Meet diariamente, respeitando os horários das aulas presenciais, com uma redução do tempo de encontro de 50 minutos para 30 minutos.

Ainda sobre a instituição privada, precisamos reforçar que foram realizados cursos de capacitação, que mesmo sendo de forma remota, auxiliaram no processo de transposição dos conteúdos para os meios virtuais. Há um suporte chegando diariamente da supervisão e coordenação pedagógica. As aulas remotas acontecem com quase 100\% de presença virtual dos alunos, mesmo no ensino fundamental. Há cobrança de responsáveis, os horários foram mantidos e tudo, dentro deste cenário possível, acontece de forma bastante proveitosa. Entendemos que a tela é fria e não há contato corporal, no entanto, ainda assim, estudantes e professores se conectam de modo que consigam estabelecer conhecimentossignificações e até mesmo uma troca de afeto e apoio.

Os estudantes se mostram ansiosos, aflitos, mas conseguem aproveitar o tempo que temos juntos para criarmos uma ligação, uma exposição da matéria ou até mesmo conversas acerca dos nossos cotidianos. As incertezas da volta às aulas, da data definitiva do Enem, de sair do tédio, são suas maiores reclamações e queixas. É possível perceber que todos têm acesso a internet, não precisam ser responsabilizados pelo lar, passando muitas vezes mais de 8 horas disponíveis para as atividades remotas. As atividades seguem seu rumo, usando ferramentas do mesmo sistema para testes e provas. Há um planejamento articulado permitindo o fechamento de notas e o calendário que segue o previsto de acordo com o planejamento inicial.

A realidade na educação pública se configura de maneira muito diferente. As diretrizes da SEEDUC (órgão responsável pela Educação no Estado do Rio de Janeiro) são difusas, sem planejamento definido, como as datas bimestrais e de avaliação. A única Revista Interinstitucional Artes de Educar. Rio de Janeiro, V. 6 - N. Especial II - p. 140-165 (jun - out 2020): "Educaç̃̃o e Democracia em Tempos de Pandemia". DOI: 10.12957/riae.2020.51880 
consistência é o uso da plataforma (Google Classroom), onde somos orientados a colocar matéria para os alunos realizarem as atividades.

No entanto, é perceptível que a adesão é muito baixa, cerca de $50 \%$ da escola que eu trabalho (dados informados pela $\mathrm{MetroV}^{\mathrm{vi}}$ ) e é nítida isso quando acessamos a plataforma e percebemos a grande evasão dos alunos. As justificativas dos alunos são as mais variadas, como: falta de computadores e notebook, não possuírem internet em casa, não possuírem dados para internet móvel, divisão de um aparelho telefônico para toda a família, afazeres domésticos, alguns precisam ir para a rua trabalhar (forma de ajudar pais desempregados). Assim, percebemos que dentro da escola pública existem muitas escolas diferentes.

Neste cenário, precisamos destacar ainda o NEJA (Novo Ensino de Jovens e Adultos), compostos em sua maioria por jovens maiores de 18 anos e pessoas com mais idade (acima dos 50 anos), esses em sua maioria precisam trabalhar para o sustento do lar e muitos outros tem dificuldade em lidar com a tecnologia, além da falta dos artefatos tecnológicos necessários a utilização da plataforma. Isso faz com que o NEJA praticamente tenha se extinguido nessa escola em que atuo, registro que existe uma turma sem nenhum acesso de alunos à plataforma.

Com essas dificuldades e percepções, observamos que para garantir o sucesso das atividades remotas precisamos transpor as dificuldades de acesso aos artefatos que permitam acessibilidade às aulas e plataformas onlines. O momento pandêmico escancara toda nossa desigualdade banalizada há anos pela sociedade. Coloca em patamares, níveis e processos totalmente distintos alunos de escola públicas e privadas, e aponta inclusive, os muitos cotidianos vividos dentro de uma mesma escola pública. As camadas de pobreza se configuram em camadas de exclusão, quanto mais pobre, mais excluído ainda dos processos formativos vigentes em tempos remotos. 
Figura 6 - Diversos cotidianos

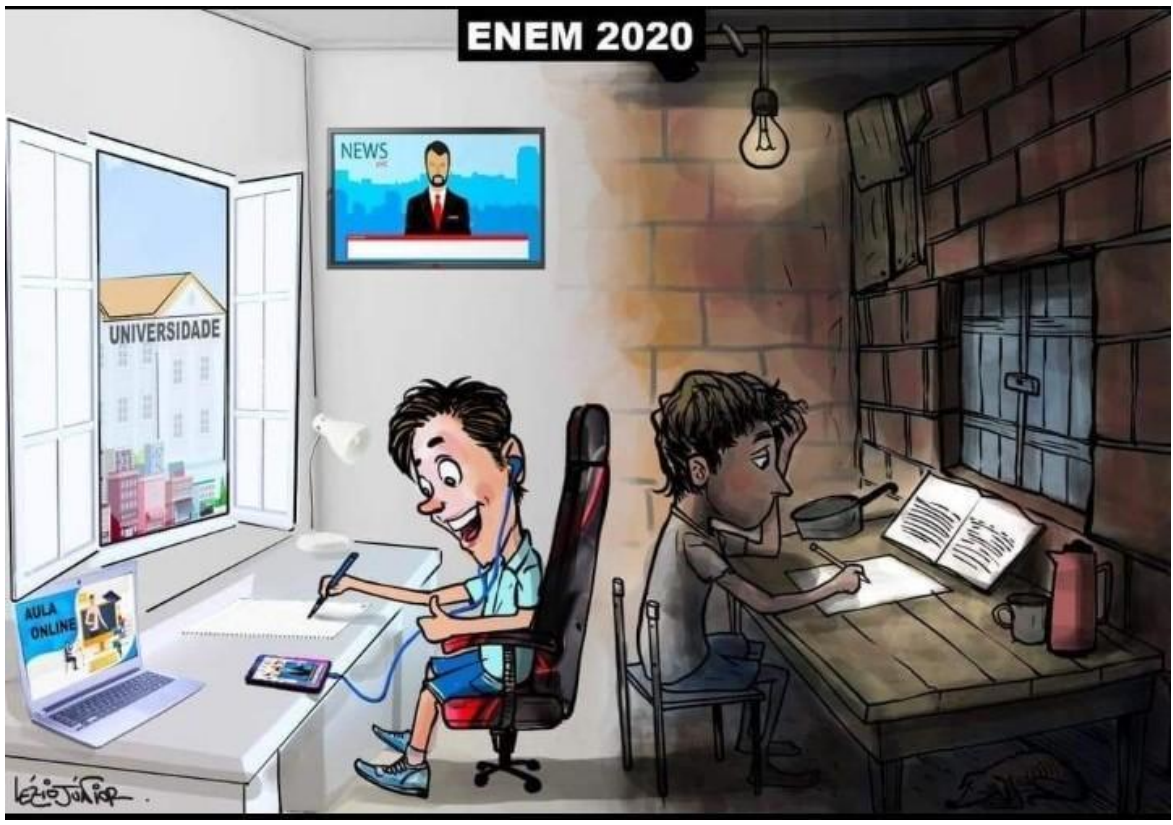

Fonte: Imagem capturada nas redes sociais da internet (whatsApp).

Contudo, vivenciamos relatos de colegas de profissão, amigos também professores e estudantes, de como tem sido difícil fazer educação em tempos remotos, mas diariamente levanta-se e mata-se um dragão por dia. Carregados de cobrança, esgotamento físico e intelectual, professores continuam produzindo, criando, se reinventando em práticas pedagógicas para seguir adiante nessa pandemia. Professores - de escolas públicas e privadas - aceitaram esse desafio e tem dado seu melhor pela continuidade do trabalho, resistem e criam cotidianamente.

\section{Educação a distância e educação remota: práticasteorias necessárias}

Atuando como mediadora do Consórcio Cederj, no curso de licenciatura em Pedagogia oferecido pela UERJ (Universidade do Estado do Rio de Janeiro), apresento um breve relato de experiência nesse contexto de pandemia. Por já trabalharmos na modalidade semi-presencial, o impacto do momento foi pequeno, embora possamos considerar perdas de imediato. E para o próximo semestre estamos providenciando remodelações em nossa disciplina para que a mesma atenda de forma mais adequada aos nossos estudantes. Esse novo modelo será pautado na experiência vivida e na avaliação realizada pelos envolvidos nos processos de ensinosaprendizagens.

Identificamos que a qualidade na interação virtual, o empenho de estudantes na busca pelo conhecimento e a dedicação de professores no sentido de tornar a interação ágil, 
assertiva, prazerosa e dinâmica são fatores potentes para alcançar o ensinoaprendizagem de qualidade.

A disciplina disponibiliza previamente textos e vídeos com o conteúdo a ser estudado. Os vídeos são mais vistos que os textos lidos e os estudantes justificam que possuem uma linguagem mais rápida de ser apreendida. Toda a plataforma pode ser acessada pelo celular e os estudantes narram que assistem aos vídeos, muitas vezes, no deslocamento de um lugar ao outro dentro do transporte público.

São facilitadores desse processo a plataforma tecnológica estruturada para dar suporte a estudantes e professores do curso e um currículo adaptado aos objetivos do mesmo, bem como estudantes e professores acostumados a interagirem no ambiente virtual sendo esses fatores diferenciais para o momento atual, pois já fazem parte de nossa prática cotidiana.

Nesse momento pandêmico, o curso que possui sua carga horária distribuída em horas presenciais e horas online, teve as presenciais canceladas e a equipe pedagógica de cada disciplina, precisou reavaliar sua estratégia de ensinoaprendizagem.

Diante da urgência, as aulas presenciais foram adaptadas para chats na plataforma e esses proporcionaram interação em tempo real com os alunos. Longe de ser a interação presencial e com o olho no olho, foi o que foi possível dentro dos recursos tecnológicos que estavam disponíveis. Optamos por não sair do ambiente virtual oferecido pelo curso acreditando que a interação com os alunos seria mais facilitada.

Essa interação proporcionou aos alunos 'conversas', porque “a oralidade está em toda parte, porque a conversação se insinua em todo lugar; ela organiza a família e a rua, o trabalho na empresa e a pesquisa nos laboratórios" (CERTEAU; GIARD: 2017, p.337). Por meio das 'conversas', que se dão a partir de situações vividas, dos vídeos que assistimos, de leituras diversas disponibilizadas na plataforma e outras,criamos condições propícias para que estudantes e professores, e nós também, como pesquisadores, tomemos conhecimento da realidade, de cada processo vivido por nossos semelhantes.

A disciplina seguiu com interações na plataforma de forma assíncrona entre mediadora e estudantes, que formaram grupos para trabalhar a pesquisa a ser realizada. Por fim, os estudantes elaboraram um relatório individual narrando a experiência, os aprendizados e as dificuldades do processo.

Dentre essas narrativas, a falta do contato inicial, onde se conhecem pessoalmente, foi apontada para a dificuldade de envolvimento no trabalho de grupo. Outra questão apontada, foi o desinteresse de alguns estudantes pelas atividades, uma vez que, não houve a aula presencial inicial mediada e com a participação de todos. 
Como ponto positivo, o contato permanente entre mediadora e estudantes esclareceu dúvidas a respeito da disciplina e da avaliação, sendo sinalizada a forma atenciosa com que as dúvidas foram sanadas.

Gostaríamos de salientar que estamos narrando um curso estruturado para a modalidade semi-presencial e no qual partimos do pressuposto de que os alunos possuem um computador, acesso à internet e experiência com os estudos nessa modalidade. Mesmo assim, não podemos afirmar que a totalidade de alunos possui esse suporte de artefatos tecnológicos. Embora o polo de apoio ao estudante possua laboratório de informática disponível para os mesmos, no momento atual, ele não está em funcionamento, o que dificulta o acesso a plataforma e exige da equipe pedagógica uma atenção especial àqueles que se encontram nessa situação.

Com o momento atual de pandemia e distanciamento social e todas as dificuldades cotidianas relatadas ao longo do texto, imagino a dificuldade de estudantes em se concentrarem em disciplinas escolares? Em se tratando de educação infantil, a dificuldade dos pequenos em realizarem tarefas online? E no caso de estudantes adultos e a maioria professoras, no caso relatado, a sobrecarga de trabalhos profissionais e domésticos.

\section{Dowload e upload em constante movimento: como democratizar se os meios não são democratizados?}

Inspirada em Alves (2008), que afirma que é preciso "narrar a vida e literaturalizar a ciência", procuramos realizar uma narrativa que valorizasse os conhecimentossignificações que não são hegemônicos e dos quais há "uma outra escritura a aprender":

Aquela que talvez se expresse com múltiplas linguagens (de sons, de imagens, de toques, de cheiros etc.) e que, talvez, não possa ser chamada mais de "escrita"; que não obedeça à linearidade de exposição, mas que teça, ao ser feita, uma rede de múltiplos, diferentes e diversos fios; que pergunte muito além de dar respostas; que duvide no próprio ato de afirmar, que diga e desdiga, que construa uma outra rede de comunicação, que indique, talvez, uma escritafala, uma falaescrita, uma falaescritafala (ALVES, 2008:30$31)$.

Não temos a intenção de criticar o esforço de nenhum profissional envolvido neste contexto, pelo contrário, evidenciar os desafios e as soluções que as pessoas vêm encontrando. É importante problematizar as questões enfrentadas por todos, principalmente em um país no qual a democratização da educação ainda não é para todos e nos atravessa pelo 
compromisso e pela responsabilidade dessa democratização, a partir do compartilhamento dos nossos modos de fazeressaberes quecontribuem de certa forma para isso.

Uma educação a distância - talvez nem a presencial - não comportam as múltiplas linguagens que Alves (2008) nos inspiram. Precisamos estar muito atentos aos momentos presentes para deixar aflorar a percepção das multilinguagens nos nossos corpos, através dos gestos, sabores e saberes. Atualmente, com as redes virtuais, as conexões aos sentidos podem ser atrofiadas, da mesma forma, podem ser potencializadas. Tudo isto depende dos usos e das intenções desses usos. São comportamentos que independem de um espaço virtual ou presencial, já que todos estes espaços são feitos por seres humanos.

Os muitos cotidianos presentes no Brasil são retrato de séculos de desigualdade social forjada pelo poderio público e estatal. A luta de classes no país ainda é uma das bandeiras mais potentes para tentarmos democratizarmos os acessos aos meios, enquanto não for possível uma equidade horizontal de oportunidades e acesso, reproduziremos uma sociedade em camadas tão profundas que sangram em momentos complexos como esses. A internet, hoje, e os meios de acesso precisam estar inseridos nas políticas públicas de educação, necessárias para qualquer possibilidade de conversa acerca do tema.

Uma educação presencial, hoje não é possível em função da pandemia. Porém, surgem questões emergentes, que nos colocam diante de desafios adormecidos e em função delas, criamos outras maneiras de aproximação. Desenvolver o equilíbrio para um futuro próximo criado a partir de uma ação presente todos os dias, onde a volta às aulas presenciais será gradativa, porém já exercitada em acontecimentos cotidianos.

A interlocução entre a educação presencial e a educação remota precisam ser enunciadas nas políticas públicas governamentais de forma que uma complemente a outra. Ambas têm muito a aprenderensinar.

Este é um grande momento de aprendizagem para toda a comunidade escolar. Não voltaremos mais iguais ao que éramos aquilo que chamávamos de "normal" nos será estranho e olharemos para trás e veremos que em alguns meses demos um salto na forma de nos relacionarmos com as redes educativas e os usos das redes sociais da internet e suas tecnologias digitais. A história é criada a partir de um passado vivido de um presente. $\mathrm{O}$ futuro é criado a partir de um presente vivido. Perceber este presente e potencializar a oportunidade de criarmos nele outras possibilidades de caminhos tortuosos, imbricados, emaranhado como as redes que tecemos nos cotidianos com nossas singularidades. 
A criação cotidiana, mesmo em tempos pandêmicos, oportunizaram novas redes, novas formas e múltiplas praticasteorias, que permearam a vida da comunidade escolar - tão acostumados aos abraços, cheiros e olhos!

Então, - Menino! Largue o celular.

$\mathrm{Ou}$, não!

\section{Referências}

ALLIENZ, E. Deleuze filosofia virtual. tradução Heloísa B.S. Rocha. São Paulo. Ed. 34.1996. ALMEIDA,W.; OLIVEIRA, R. \& SANTOS, E. A discursividade dos memes- mimetizandose nas redes educativas. Revista Periferia - Educação, Cultura e Comunicação, 2019. p. 5789.

ALVES, N. Decifrando o Pergaminho - os cotidianos das escolas nas lógicas das redes cotidianas. In: ALVES, N.; OLIVEIRA, I. B. de (Orgs.). Pesquisa nos/dos/com os cotidianos das escolas - sobre redes de saberes. Petrópolis: DP et Alii, 2008:p 31 - p 32.

ALVES, N. Redes educativas, fluxos culturais e trabalho docente: o caso do cinema suas imagens e sons. Financiamentos CNPq, FAPERJ e UERJ, 2012-2017. 2012. (Projeto de Pesquisa).

ALVES, N. A formação com as imagens. Revista Interinstitucional Artes de Educar. Rio de Janeiro, V. 2 N. Especial - jun. out. 2016, p. 235-252 .

ALVES, N.; ANDRADE, N.; CALDAS, A. N. Os movimentos necessários às pesquisas com os cotidianos. In OLIVEIRA, I. B. de; SUSSUKIND, M. L.; PEIXOTO, L. (orgs). Estudos do cotidiano, currículo e formação docente questões metodológicas, políticas e epistemológicas. Curitiba: CRV, 2019: p 1 - 22.

BARBERO, J. M. Novos regimes de visualidade e descentramentos culturais. In: FILÉ, V. Batuques, fragmentações e fluxos: zapeando pela linguagem audiovisual escolar. Rio de Janeiro: DP\&A, 2000. p. 83-112.

CERTEAU, M. de. A invenção do cotidiano - 1. Artes de fazer. Petrópolis/RJ: Vozes, 2012.

CERTEAU, M. de; GIARD, L.; MAYOL, P. A invenção do cotidiano: 2. Morar, cozinhar. Petrópolis, RJ: Vozes, 9a Ed., 2017, p 336 - p 338.

DELEUZE, G.; GUATTARI, F. Personagens conceituais. In DELEUZE, G. e GATTARI, F. O que é filosofia? Rio de Janeiro: Ed 34, 1992: 81-109.

FREIRE, P. Pedagogia da autonomia: saberes necessários à prática educativa. São Paulo: Paz e Terra, (1996). (coleção Leitura)

GUATTARI, Felix. Três ecologias.São Paulo: Papirus, 1997. 
LATOUR, B. Imaginar gestos que barrem o retorno da produção pré-crise. Tradução: Débora Danowski e Eduardo Viveiros de Castro. Disponível em: https://n-1edicoes.org/0081. Acesso em: 06 abr. 2020.

MATURANA H. Emoções e Linguagem na educação e na política. Ed UFMG, Belo Horizonte 2002.

SANTOS, E. Pesquisa-formação na cibercultura / Edméa Santos. - Teresina: EDUFPI, 2019.

RODRIGUES, F. S., SEGUNDO, G. L. S., RIBEIRO, L. M. da S. O Uso do Celular na Sala de Aula e a Legislação Vigente no Brasil. In: III Congresso sobre tecnologias na Educação (Control E + 2018). Fortaleza, Ceará, Brasil. 2018. Dispovivel em: http://ceur-ws.org/Vol2185/CtrlE 2018 paper 32.pdf. Acessado em 02 jun. 2020.

\section{Acessos online:}

Revista Desafios da Educação. Disponível em: https://desafiosdaeducacao.grupoa.com.br/coronavirus-ensino-remoto/. Acesso: em 08 jun. 2020.

\footnotetext{
i Doutorando em Educação do ProPEd-UERJ, Mestre em Processos formativos e desigualdade social (FFP/UERJ). Geógrafo pela UFRF. E-mail: mar_chado@hotmail.com .ORCID https://orcid.org/0000-00017845-7340

${ }^{\text {ii }}$ Doutoranda em Educação pelo ProPEd-UERJ, Mestre em Educação pela ProPEd-UERJ. Mediadora do curso de pedagogia do consórcio Cederj/UERJ. Pedagoga pela UFRJ. E-mail: mariamoraiss@yahoo.com.br . ORCID https://orcid.org/0000-0001-7845-7340
}

${ }^{\text {iii }}$ Doutoranda em Educação pelo ProPEd-UERJ. Desenvolve projetos nas áreas das artes e tecnologias. E-mail: noatetoja22@gmail.com. Todos os autores fazem parte do Grupo de Pesquisa Currículos e Cotidiano e Redes Educativas e Imagens e sons e são bolsistas FAPERJ. ORCID https://orcid.org/0000-0002-1207-2795

${ }^{\text {iv }}$ É prática comum entre os pesquisadores cotidianistas fazer o uso de neologismos quando as palavras em nossa língua não conseguem dar sentido ao que queremos expressar. Neste caso, por exemplo, unimos os verbos ver, sentir e pensar, pois, acreditamos que esta ação ocorre ao mesmo tempo, sem uma determinada hierarquização das ações. Também é comum unirmos palavras aparentemente dicotômicas como práticateoria ou políticaprática. Por se tratarem de neologismos, estas palavras serão grafadas em itálico.

${ }^{v}$ Site do Museu:https://www.museudememes.com.br/v

${ }^{v i}$ Significa Metropolitana V, que é uma divisão existente na SEEDUC para organização das escolas, corresponde ao Município de Duque de Caxias/RJ 